\title{
A QUANTITATIVE ANALYSIS OF ROTARY, ULTRASONIC AND MANUAL TECHNIQUES TO TREAT PROXIMALLY FLATTENED ROOT CANALS
}

\author{
Fabiana Soares GRECCA ${ }^{1}$, Roberto Brandão GARCIA ${ }^{2}$, Clóvis Monteiro BRAMANTE ${ }^{3}$, \\ Ivaldo Gomes de MORAES ${ }^{4}$, Norberti BERNARDINELI ${ }^{5}$
}

\author{
1- DDS, PhD, Department of Endodontics, School of Dentistry of Porto Alegre, Federal University of Rio Grande do Sul, Porto Alegre RS, Brazil. \\ 2- DDS, PhD, Department of Endodontics, Bauru School of Dentistry, São Paulo State University, Bauru, SP, Brazil. \\ 3- DDS, PhD, Professor of Endodontics at Bauru School of Dentistry, University of São Paulo, Bauru, São Paulo, Brazil. \\ 4- DDS, PhD, Associate Professor of the Discipline of Endodontics, Bauru School of Dentistry, University of São Paulo, Bauru, São Paulo, Brazil. \\ 5- DDS, PhD, Professor of the Discipline of Endodontics, Bauru School of Dentistry, University of São Paulo, Bauru, São Paulo, Brazil. \\ Corresponding address: Fabiana Soares Grecca - Rua Cel. Lucas de Oliveira, 600/202 - Porto Alegre, RS. 90440-011 \\ Phone: 555137375220 - e-mail: fakera@terra.com.br \\ Received: August 06, 2005 - Modification: December 14, 2006 - Accepted: March 02, 2007
}

\begin{abstract}
$O$

bjective: The efficiency of rotary, manual and ultrasonic root canal instrumentation techniques was investigated in proximally flattened root canals.

Material and Methods: Forty human mandibular left and right central incisors, lateral incisors and premolars were used. The pulp tissue was removed and the root canals were filled with red die. Teeth were instrumented using three techniques: (i) K3 and ProTaper rotary systems; (ii) ultrasonic crown-down technique; and (iii) progressive manual technique. Roots were bisected longitudinally in a buccolingual direction. The instrumented canal walls were digitally captured and the images obtained were analyzed using the Sigma Scan software. Canal walls were evaluated for total canal wall area versus noninstrumented area on which dye remained.

Results: No statistically significant difference was found between the instrumentation techniques studied $(\mathrm{p}<0.05)$.

Conclusion: The findings of this study showed that no instrumentation technique was $100 \%$ efficient to remove the dye.
\end{abstract}

Uniterms: Endodontics; Instrumentation; Root canal; Rotary systems.

\section{INTRODUCTION}

The mechanical preparation of root canals plays a significant role in endodontic therapy. The process involves the removal of pulp cavity content and the consequent reduction of microorganism counts, especially in non-vital teeth with periapical lesion. With proper instrumentation, the cavity is enlarged and smoothened to fittingly receive the filling. As tooth and canal anatomies are equally important during canal preparation, the appropriate use of the endodontic instruments and the close contact with canal walls for pulp extirpation and cleaning purposes is likewise crucial to the treatment. Several techniques and instruments have been suggested to achieve the desired efficiency in root canal preparation ${ }^{2,6,11,15,19,23}$. The concomitant use of chemicals that promote the removal of microorganisms is widely accepted. As regards the cleaning and disinfection of root canals, current literature sets forward conflicting results for manual, mechanical and ultrasonic

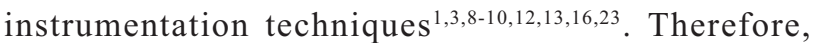
considering that in the treatment of non-vital teeth with chronic periapical reaction the presence of bacteria inside the root canal system accounts for the development and persistence of periapical lesions, this study was designed to investigate quantitatively the in vitro ability to remove dye adhered to proximally flattened root canals. Three techniques were investigated: Crown-down technique with rotary instrumentation using nickel-titanium files (K3 and ProTaper systems); ultrasonic crown-down technique; and progressive manual technique without apical pressure modified Oregon technique.

\section{MATERIALAND METHODS}

A set of 40 permanent human teeth freshly extracted from patients at the University of Marília for periodontal or prosthetic purposes and stored in $0.01 \%$ thymol solution 
was used in this study. Teeth were mandibular left and right central incisors and lateral incisors, and mandibular right and left premolars, evenly distributed the groups. All teeth presented proximally flattened root canals. Coronal openings were drilled and the pulp content removed. Apical foramina were cleared using a no. $10 \mathrm{~K}$-file (Dentsply Maillefer, Ballaigues, Switzerland).

Canals were filled with red dye (Acrilex S.A., São Paulo, SP, Brazil) using an insulin syringe (Becton Dickinson, Curitiba, PR, Brazil), upon the foramen. A fine Kerr file was then repetitively pumped in the canal to prevent the formation of bubbles, whereupon teeth were left to rest at room temperature for $48 \mathrm{~h}$ to ensure complete curing of red dye. Next, teeth were subdivided into 4 groups with 10 teeth each. The groups were instrumented using three different techniques. Group I was treated with the crown-down technique using the K3 system (Kerr, Sybron Endo, California, USA) (Table 1) and Group II with the crowndown technique using the ProTaper system (Dentsply Maillefer, Ballaigues, Switzerland) (Table 2); Group III was treated with the progressive manual technique without apical pressure (modified Oregon technique); and Group IV was treated with the ultrasonic crown-down technique. All techniques were applied at $1 \mathrm{~mm}$ short of working length.

The root canal walls of Groups I and II were instrumented using an electric endodontic engine (Endo Plus K; VK Driller Equipamentos Elétricos, São Paulo, SP, Brazil). The device was adjusted to a constant clockwise 250-rpm speed and to a \#3 torque. Group III was instrumented using the modified Oregon technique as defined by Berbert, et al. ${ }^{2}$ (1996). The working length was kept patent to files between 30 and 35 . Group IV was instrumented using the ultrasonic crown-down technique. The process started using a manual size $40 \mathrm{~K}$-file adapted to a ultrasound device (Enac; Osada Electric Co, Japan), energized for $1 \mathrm{~min}$. From this point on, smaller files were progressively used to ensure that the desired canal working length was reached. The working length was kept patent to files between sizes 30 and 35. Circular, slow and short filing movements were used.

For all groups, canals were flushed with $1.8 \mathrm{~mL} \mathrm{2.5 \%}$ sodium hypochlorite (Chemical Institute of Marilia, UNIMAR, Marilia, SP, Brazil) at each change of file. Each instrument was used 5 times and then discarded.

The canals were then dried using paper points (Tanari Industrial Ltda, Manaus, AM, Brazil) and the teeth were decoronated length-wise in a buccolingual direction using a diamond disk. Halves were tagged with the root number and experimental group identification.

The efficiency of each instrumentation technique under study was measured by assessing quantitatively the amount of dye that remained on the root canal walls. Halves containing the root canal dentin walls were digitally captured using a desk scanner (Genius ColorPage-Vivid Pro II) coupled to a Pentium IV computer equipped with the MGI PhotoSuit

TABLE 1- Sequence for the crown-down technique using the K3 system

\begin{tabular}{|c|c|c|}
\hline Crown-down instrumentation & Instrument & Taper \\
\hline Cervical third & Orifice opener 1 and 2 & 25.10 and 25.08 \\
\hline \multirow[t]{6}{*}{ Middle and apical third } & 30 & 0.06 \\
\hline & 25 & 0.06 \\
\hline & 20 & 0.06 \\
\hline & 30 & 0.04 \\
\hline & 25 & 0.04 \\
\hline & 20 & 0.04 \\
\hline Working length & 25 & 0.04 \\
\hline
\end{tabular}

TABLE 2- Sequence for the crown-down technique using the Pro Taper system

\begin{tabular}{lcc}
\hline Crown-down instrumentation & Instrument & Anatomic diameter \\
\hline Cervical third & SX & \\
\hline Middle and apical third & S1 & 20 \\
& S2 & 25 \\
Working length & F1 & 30 \\
\hline
\end{tabular}


software. Once resolution, brightness and contrast features were standardized, images were accessed using the Sigma Scan software (Jandel Scientific Corporation, San Rafael, CA). This software was used to evaluate the measurements recorded for each instrumented root canal. Total canal area was obtained $\left(\mathrm{mm}^{2}\right)$ and the uninstrumented canal areas that remained stained with the dye were determined. Data were entered into a Windows Excell 2000 spreadsheet, affording the quantification of dye that remained after instrumentation by the percentile difference between total root canal area and the dye-stained uninstrumented canal area.

As data met the requirements of normal distribution and variance homogeneity, one-way ANOVA was used to compare statistically the four experimental groups at 5\% significance level.

\section{RESULTS}

The quantitative analysis of the data obtained for the total root canal area and the dye-stained uninstrumented canal areas, as well as the percentile difference between them are shown on Figure 1.

Table 3 shows the results of the $\mathrm{F}$ distribution for the percentile difference between the total root canal area and the dye-stained uninstrumented canal area. .

No statistically significant difference were found between the groups $(p=0.101$ and $\mathrm{F}=2.23)$.

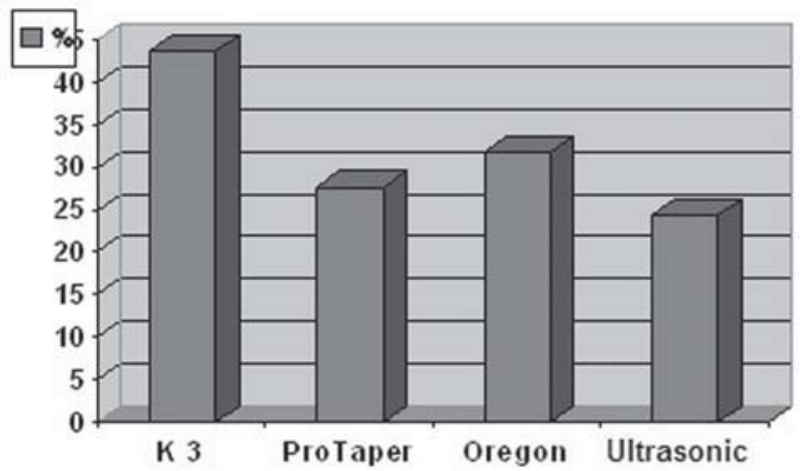

FIGURE 1- Quantitative analysis of the percentile difference obtained for the total root canal area and remaining dye on non-instrumented area

\section{DISCUSSION}

Root canal instrumentation is not a simple procedure and demands manual skills as well as deep knowledge of the internal root canal system. The preparation of curved root canals and root canals with isthmuses is more complex because the instrument suffers the tensions and deformations imposed by the procedure, which can ultimately influence the outcomes of the root canal treatment.

The experimental model adopted in the present study, using natural human teeth, was chosen because their root canal anatomy is remarkably flattened and irregular. This aspect of human root canals may pose additional difficulties to instrumentation and challenge the treatment outcomes because complete removal of remaining tissues from isthmus areas is sometimes hard to achieve $\mathrm{e}^{9,13,23}$

Different methods to evaluate instrumentation techniques and their results have been reviewed in the literature. Among the methodologies adopted to investigate root canal preparation methods are scanning electronic microscopy ${ }^{3,8,10,23}$, simulated polyester resin root canals ${ }^{22}$, computer software ${ }^{5}$ and clearing ${ }^{17}$.

Gonçalves $\mathrm{Jr}^{9}$ (2003) and Silva, et al. ${ }^{19}$ (2004) used root canal dye techniques to compare instrumentation protocols with respect to efficiency and instrumented area. In the present study, the methodology adopted enabled the removal of the dye by the instruments used. It is important to mention that the dye used was proved to be insoluble in water, which makes each instrumentation technique the sole dye removal agent in the study. Image digitization of the halves and dyestained areas on the root canal walls allowed the in-depth analysis of experimental results. Although these are twodimensional images, the fact that the specimens present well-defined mesiodistal flattened root canals, with minimal depth $^{9}$ validates the use of the two-dimensional image approach.

Table 3 and Figure 1 show how the extension of the dyestained root canal area increases from Group IV (Ultrasonic) to Group II (ProTaper), III (Oregon) and I (K3), in this sequence. These results allowed observing that none of the adopted techniques was efficient enough to completely remove the dye adhered to the canal walls. Similar results have been reported by Barbizam, et al. ${ }^{1}$ (2002) and Zmener, et al. ${ }^{23}$ (2005).

Table 3 shows that, although no statistically significant difference was observed between the groups, the

TABLE 3- Frequency, means and standard deviation of the percentile difference between the total root canal area and the dye-stained uninstrumented canal area, for each instrumentation technique

\begin{tabular}{lccc}
\hline Group & Frequency & Mean & Standard deviation \\
\hline I (K3) & 10 & 39.76 & 14.34 \\
II (ProTaper) & 10 & 23.31 & 17.71 \\
III (Oregon) & 10 & 29.04 & 14.30 \\
IV (Ultrasonic) & 10 & 22.95 & 19.45 \\
\hline
\end{tabular}


instruments that reached the root canal walls and isthmuses more effectively produced better results in canal preparation. This was observed with the manual and ultrasonic techniques. Nevertheless, given that rotary instrumentation systems tend to operate more centrally inside the root canal $^{7,9}$ and considering that the root canals prepared in the present study were flattened, the performance of the ProTaper system (Group II, Table 3) is worth mentioning. The ProTaper system produced significantly better instrumentation than the K3 system (Group I, Table 3). This is contrary to what is ordinarily expected of Oregon and ultrasonic techniques.

K3 and ProTaper techniques have differently tapered rotary instruments to operate on the cervical third and produced considerably different results in the present study. While the K3 system exhibited the worst result among the four groups (mean=39.76), the ProTaper system produced a good instrumentation $($ mean $=23.31)($ Table 3$)$. This is probably due to the gradually tapered instrument design of ProTaper files, as tapering ranges from 0.02 to $0.12 \mathrm{~mm}$ from its end D1 to base D2. Therefore, each instrument reaches a different canal area ${ }^{21}$. In terms of cleaning ability, the active instruments (ProTaper) appeared to remove the smear layer more effectively than instruments with radial lands (K3).

The use of the Ultrasonic technique (Group IV, Table 3) produced a satisfactory result for removal of the dye-stained dentin. This is due to the adoption of the crown-down instrumentation, which started with greater file sizes. It is worth mentioning that thicker instruments tend to be more efficient, removing larger amounts of dentin within shorter times. These findings agree with those of Esberard, et al. ${ }^{6}$ (1987), who suggested the need for a closer contact between the instrument and canal walls for optimal dentin removal. In the present study, irrigation was performed constantly during instrumentation, but rather at each instrument change. This procedure was adopted to allow a better comparison between techniques, as these techniques do not intrinsically use irrigation. The results also showed that the ultrasonic technique without constant irrigation proved to be the most efficient technique.

The enlargement of the cervical third before instrumentation of the apical region had a positive effect on the performance of the techniques because the influence of dentin thickness is lessened, thus favoring the full-length direct action of instruments along the canal walls. This is agrees with the findings of other studies ${ }^{14,20}$. Furthermore, Shovelton ${ }^{18}$ (1964) demonstrated that in addition to dentin contamination, large bacterial counts are found along this portion of the canal. In the present study, the cervical region of all teeth was prepared, by either rotary instruments with accentuate taper or Gates-Glidden drills (for the modified Oregon technique), or even files with larger sizes, as those used for the ultrasonic technique.

The use of Gates-Glidden drills has a beneficial effect on root canal preparation and plays an important role in the cleaning of the cervical third of the canal. The results of the present contradict those of previous investigations in which the modified Oregon technique (Group III) was shown to produce better results than ultrasonic, Canal Finder and ProFile rotary techniques ${ }^{9,16}$, when the canal were preflared with Gates-Glidden drills.

In the present study, the progression of instrumentation without apical pressure had little contribution on the cleaning of polar and isthmus zones. Progressive instrumentation works smoothly and harmoniously for the benefit of root canal preparation as a whole. Root canal enlargement allows introducing the files further into the canal, in contact with the dentin walls. Yet, it is not possible to direct the action of the instruments, differently from what is observed for the filing movement.

Based on the number of remaining dye-stained areas on the canal walls, the outcomes of this study demonstrated that none of the techniques produced an appropriate canal preparation. These results contradict the findings of Canzani, et al. ${ }^{4}$ (1984). Portions of the canal walls that were untouched by the instruments, such as isthmuses, were often found in all groups. This is imputable to both the inefficiency of the technique and the anatomic abnormalities, even in a technologic scenario that affords a variety of rotary instruments of diverse characteristics ${ }^{10}$. In a comparative investigation that assessed manual instrumentation, sonic and ultrasonic techniques, Langeland, et al. ${ }^{12}$ (1985) affirmed that canal anatomy plays a more important role in endodontic treatment than any instrumentation technique. The authors reported that although the techniques cleaned straight, tubular canals, they failed to reach the same efficiency for curved, irregular canals.

Therefore, it is important to take into account that all instrumentation techniques demand more attention in the treatment of teeth with pulp necrosis and periapical lesion, in which contamination is wide-ranging and intense, with consequent demand for intracanal dressings and sealing.

\section{CONCLUSIONS}

In the light of the results obtained in the present study, it was observed that: (i) no instrumentation technique fully removed all dye-stained areas from the canal walls; (ii) the quantitative assessment of dye removal from the canal walls did not show statistically significant difference between the studied groups $(\mathrm{p}<0.05)$; (ii) the ideal instrumentation technique for curved and irregular root canals has not yet been made available.

\section{REFERENCES}

1-Barbizam JVB, Fariniuk LF, Marchesan MA, Pécora JD, Sousa M Neto. Effectiveness of manual and rotary instrumentation techniques for cleaning flattened root canals. J Endod. 2002;28(5):365-6.

2- Berbert A, Bramante CM, Bernardineli N, Moraes IG, Garcia RB. Técnica de Oregon modificada. Rev Gauch Odontol. 1996;44(3):1412 .

3- Bolanos OR, Jensen JR. Scanning electron microscope comparisons of the efficacy of various methods of root canal preparation. J Endod. 1980;6(11):815-22. 
4- Canzani JH, Fernández EG, Testa R, Santra C, Fusaro E, Herbel B. Empleo de la técnica escalonada y el ensanchador mecánico en la preparación de los conductos radiculares. Rev Asoc Odontol Argent. $1984 ; 72(2): 40-2$.

5- Chan AWK, Cheung GSP. A comparison of stainless steel and nickel-titanium $\mathrm{K}$-files in curved root canals. Int Endod J. 1996;29(6):370-5.

6- Esberard RM, Leonardo MR, Leal JM, Simões AP Filho, Bonetti I Filho. O ultrasom em endodontia: vantagens e desvantagens. Rev Gauch Odontol. 1987;35(4):297-300.

7- Fabra Campos H, Monteverde Rovira S, Chordá Martinez V. Técnica escalonada manual versus um nuevo sistema mecánico (Profile.04) em la preparación de conductos radiculares. Endodoncia. $1998 ; 16(1): 21-7$

8- Foschi F, Nucci C, Montebugnoli L, Marchionni S, Breschi L, Malagnino VA, et al. SEM evaluation of canal wall dentine following use of Mtwo and ProTaper NiTi rotary instruments. Int Endod J. 2004;37(12):832-9.

9- Gonçalves JF Jr. Análise comparativa entre o sistema Profile .04/ 06 e a técnica Oregon modificada na remoção de corante aderido às paredes de canais radiculares achatados [tese]. Bauru (SP): Faculdade de Odontologia de Bauru, Universidade de São Paulo; 2003.

10- Heard F, Walton RE. Scanning electron microscope study comparing four root canal preparation techniques in small curved canal. J Endod. 1997;30(5):323-31.

11- Kherlakian D, Ferreira MOF, Zuolo ML. Quantec 2000: uma nova técnica para a instrumentação de canais. Rev Assoc Paul Cir Dent. 1997;51(4):333-7.

12- Langeland K, Liao KKS, Pascon EA. Work saving devices in endodontics: efficacy of sonic and ultrasonic techniques. J Endod. 1985;11(11):499-510.

13- Maniglia CAG, Biffi JCG. Avaliação do volume do canal radicular após as instrumentações manual e ultrassônica. Rev Assoc Paul Cir Dent. 1995;49(4):291-4

14- McCann JT, Keller DL, Labounty G.L. Remaining dentin/ cementum thickness after hand or ultrasonic instrumentation. J Endod. 1990;16(3):109-13.

15- McSpadden JT. Une nouvelle approche pour la preparation et 1'obturation canalaire. Endo Revue Française d'Endodontie. 1993;12(1):9-19.

16- Nishiyama CK, Garcia RB. Estudo comparativo entre as técnicas de instrumentação escalonada regressiva, oregon modificada, sistema canal finder e canal master U na limpeza de canais radiculares. Rev Odontol Univ São Paulo. 1993;7(3):173-9.

17- Pesce HF, Medeiros JMF, Moura AAM. Análise morfológica comparativa do preparo de canais radiculares curvos com dois tipos de instrumentos endodônticos. Rev Odontol Univ São Paulo. 1997;11(2):87-91.

18- Shovelton DS. The presence and distribution of microorganisms within non-vital teeth. Br Dent J. 1964;117(3):101-7.

19- Silva LA, Leonardo MR, Nelson P Filho, Tanomaru JM. Comparison of rotary and manual instrumentation techniques on cleaning capacity and instrumentation time in deciduous molars. J Dent Child. 2004;71(1):45-7.

20- Swindle RB, Neaverth EJ, Pantera EA, Ringle RD. Effect of coronal-radicular flaring on apical transportation. J Endod. $1991 ; 17(4): 147-9$.
21- Sydney GB. Como preparar o canal radicular com rapidez e eficiência. In: Cardoso RJA, Gonçalves EAN. Endodontia/Trauma. São Paulo: Artes Médicas; 2002. p. 189-218.

22- Thompson SA, Dummer PMH. Shapin ability of ProFile .04 Taper series 29 rotary nickel-titanium instruments in simulated root canals. Part 1. Int Endod J. 1997;30(1):1-7.

23- Zmener O, Pamejer CH, Banegas G. Effectiveness in clearing oval-shaped root canals using anatomic endodontic technology, profile and manual instrumentation: a scanning electron microscopy study. Int Endod J. 2005;38(6):356-63. 